\title{
Mantle flow and melting underneath oblique and ultraslow mid-ocean ridges
}

\author{
Laurent G. J. Montési ${ }^{1,2}$ and Mark D. Behn ${ }^{1}$ \\ Received 20 June 2007; revised 10 October 2007; accepted 25 October 2007; published 25 December 2007.
}

[1] Mid-ocean ridge morphology correlates strongly with spreading rate. As the spreading rate decreases, conductive cooling becomes more important in controlling ridge thermal structure and the axial lithosphere thickens. At ultraslow spreading rates, the ridge axis becomes sufficiently cold that peridotite blocks are emplaced directly at the seafloor and volcanism is limited to localized volcanic centers widely spaced along the ridge axis. Some slow-spreading ridges adopt an ultraslow morphology when their axis is oblique to the spreading direction. We present an analytical solution for mantle flow beneath an oblique ridge and demonstrate that the thermal structure and crustal thickness are controlled by the effective spreading rate (product of the plate separation velocity and the cosine of obliquity). A global compilation of oblique ridges reveals that ultraslow morphology corresponds to effective half rates less than $6.5 \mathrm{~mm} / \mathrm{yr}$, resulting in lithosphere that is thicker than $\sim 30 \mathrm{~km}$. We conclude that the transition from slow to ultraslow spreading is not related to a change of melt productivity but rather in the efficiency of vertical melt extraction. Citation: Montési, L. G. J., and M. D. Behn (2007), Mantle flow and melting underneath oblique and ultraslow mid-ocean ridges, Geophys. Res. Lett., 34, L24307, doi:10.1029/2007GL031067.

\section{Morphology of Slow and Ultraslow Ridges}

[2] At all spreading rates, mid-ocean ridges display alongstrike variations in tectonic faulting and magmatic accretion, expressed in particular as ridge offsets. At slow spreading rates, ridge segmentation likely reflects buoyancy driven instabilities in the upwelling mantle modulated by variations in lithosphere thickness, hydrothermal circulation, and fracturing [e.g., Lin and Parmentier, 1990; Phipps Morgan and Chen, 1993]. As spreading rate decreases, the magnitude of crustal thickness variations along individual segments becomes greater [Lin and Phipps Morgan, 1992]. However, at the slowest spreading rates (i.e., ultraslow) an altogether different mode of seafloor spreading appears in which crustal accretion is not continuous along axis [Dick et al., 2003].

[3] We view the arctic Gakkel ridge east of $3^{\circ} \mathrm{E}$ as the type locality for ultraslow spreading (Table 1) [Michael et al., 2003]. Volcanism along the Gakkel ridge is limited to $\sim 40 \mathrm{~km}$ long localized volcanic centers spaced every 80 to $180 \mathrm{~km}$. Blocks of mantle peridotite are emplaced directly at

\footnotetext{
${ }^{1}$ Department of Marine Geology and Geophysics, Woods Hole Oceanographic Institution, Woods Hole, Massachusetts, USA.

${ }^{2}$ Now at Department of Geology, University of Maryland at College Park, Maryland, USA.
}

Copyright 2007 by the American Geophysical Union. 0094-8276/07/2007GL031067\$05.00 the seafloor between the volcanic centers, and transform discontinuities are absent.

[4] Ultraslow spreading may also result from high ridge obliquity. We define the obliquity angle $\gamma$ between the direction of plate separation and the normal to the ridge axis. Most ridge segments are orthogonal $(\gamma=0)$ but many oblique segments have been identified [Atwater and Macdonald, 1977; Taylor et al., 1994], especially at the slowest ridges.

[5] The Mohns [Dauteuil and Brun, 1993; Klingerhöfer et al., 2000] and Reykjanes [Searle et al., 1998] Ridges are examples of slow-spreading oblique ridges. Volcanism is continuous along axis in the form of axial volcanic ridges, which probably reflect dike injection [Mendel et al., 2003]. By contrast, the highly oblique $9^{\circ}-16^{\circ} \mathrm{E}$ segment of the Southwest Indian Ridge (SWIR, Figure 1) displays localized volcanic centers separated by amagmatic segments, similar to the ultraslow parts of the Gakkel Ridge [Dick et al., 2003]. Peridotite blocks occupy most of the rift valley and gravity and magnetic data imply thin or absent crust beneath the amagmatic segments [Dick et al., 2003]. This ultraslow morphology contrasts with the neighboring $16^{\circ}-25^{\circ} \mathrm{E}$ segment of the SWIR, where spreading is orthogonal and the axis displays slow spreading morphology (Figure 1) [Dick et al., 2003]. Similar correlations between obliquity and crustal thickness are observed at the SWIR $54^{\circ}-57^{\circ} \mathrm{E}$ area [Sauter et al., 2004].

[6] To understand how spreading rate and obliquity influence the transition from slow or ultraslow spreading, we conducted a global survey of the slowest and most oblique ridge segments described in the literature (Table S1 in auxiliary material). ${ }^{1}$ We classified each segment as slow or ultraslow based on the continuity of volcanism. This compilation reveals that neither obliquity nor spreading rate alone differentiate slow from ultraslow ridges as fully as the effective spreading rate (Figure 2), defined as the component of plate motion perpendicular to the spreading axis,

$$
V_{E}=V_{P} \cos \gamma
$$

where $V_{P}$ is the plate separation half-rate.

[7] Ultraslow spreading has been previously associated with $V_{P}<10 \mathrm{~mm} / \mathrm{yr}$ [Dick et al., 2003; Cannat et al., 2006] based on the occurrence of crust thinner than $6 \mathrm{~km}$ [White et al., 2001]. However, we find that associating ultraslow spreading with the lack of continuous volcanism implies instead a slower critical effective spreading rate $V_{E} \sim 6.5 \pm$ $0.3 \mathrm{~mm} / \mathrm{yr}$. The Gakkel Ridge [Michael et al., 2003] and the SWIR $61^{\circ}-65^{\circ} \mathrm{E}$ area [Cannat et al., 2006] are close to this

\footnotetext{
${ }^{1}$ Auxiliary materials are available in the HTML. doi:10.1029/ 2007 GL031067.
} 
Table 1. Characteristics of Slow and Ultraslow Ridges

\begin{tabular}{lll}
\hline \multicolumn{1}{c}{ Characteristic } & \multicolumn{1}{c}{ Slow } & \multicolumn{1}{c}{ Ultraslow } \\
\hline Effective Spreading Rate & $>6.5 \mathrm{~mm} / \mathrm{yr}$ & $<6.5 \mathrm{~mm} / \mathrm{yr}$ \\
Type Orthogonal Area & MAR & Gakkel \\
Type Oblique Area & Mohns & SWIR $9^{\circ}-16^{\circ} \mathrm{E}$ \\
Focused Volcanic Centers & Yes & Yes \\
Amagmatic Segments & No & Yes \\
Crustal Thickness & 3 to $6 \mathrm{~km}$ & $<4 \mathrm{~km}$ \\
Rift Flanking Faults & Yes & Yes \\
En-échelon AVR & Yes & No \\
Lithosphere Thickness & 5 to $10 \mathrm{~km}$ & $10-30 \mathrm{~km}$ \\
Melt Focusing & Present & Intense \\
\hline
\end{tabular}

threshold and display short-lived and short-wavelength transitions between slow and ultraslow morphology.

[8] Using a geometrical argument, previous studies proposed that the effective spreading rate should control upwelling below an oblique spreading center [Vogt et al., 1969; Cannat et al., 1999; Dick et al., 2003]. Below, we confirm the importance of the effective spreading rate with an analytical solution of mantle flow underneath oblique ridges and discuss its implications for melt production and extraction. This analysis suggests that the transition from slow to ultraslow spreading corresponds to a change in vertical melt extraction efficiency rather than melt production.

\section{Mantle Flow Beneath Oblique Spreading Centers}

[9] Melting at mid-ocean ridges results from decompression of mantle that rises underneath the spreading center.
Here, we generalize the standard corner flow model [Batchelor, 1967; McKenzie, 1969] to consider oblique spreading. We consider an infinitely long ridge axis aligned along the $y$ direction of a Cartesian reference frame. The $x$ axis is perpendicular to the ridge axis while the $z$ axis (depth) points downward (Figure 3).

[10] The separation of the surface plates, with half rate $V_{P}$ and obliquity angle $\gamma$, is imposed at the surface $z=0$

$$
\left\{\begin{array}{l}
v_{x}= \pm V_{p} \cos \gamma= \pm V_{E} \\
v_{y}= \pm V_{p} \sin \gamma= \pm V_{S} \\
v_{z}=0
\end{array}\right.
$$

[11] Because the ridge is infinite, the model is invariant in the $y$ direction. Therefore, $3 \mathrm{D}$ mass conservation reduces to a relation between the velocity components in the ridgeperpendicular plane

$$
\frac{\partial v_{x}}{\partial x}+\frac{\partial v_{z}}{\partial z}=0
$$

which is automatically verified if these components result from a 2D flow potential $\phi$.

[12] Assuming that the mantle has uniform viscosity, momentum conservation produces a pair of totally decoupled and independent equations

$$
\left\{\begin{array}{l}
\nabla^{4} \phi=0 \\
\nabla^{2} v_{y}=0
\end{array}\right.
$$

\section{Oblique supersegment}

\section{Orthogonal supersegment}

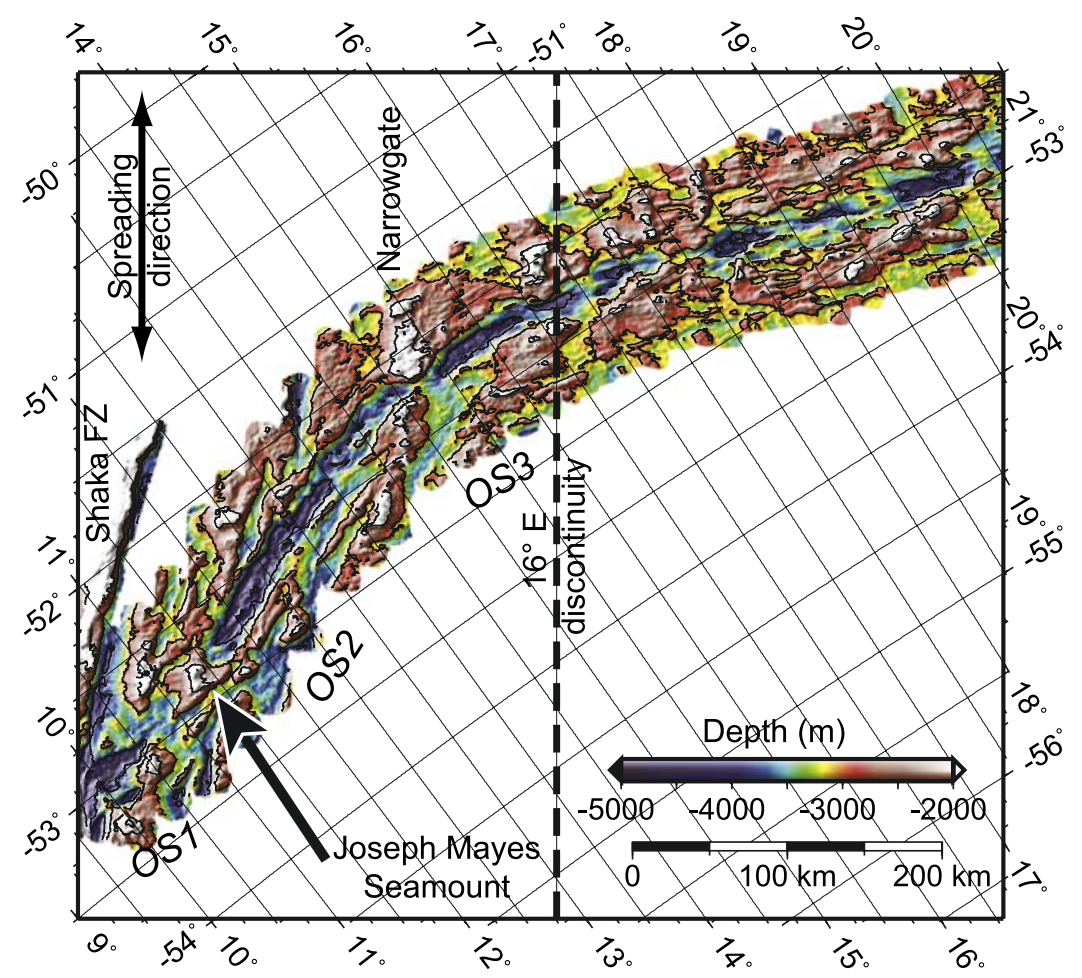

Figure 1. Bathymetric map of the SWIR at $9^{\circ}-21^{\circ} \mathrm{E}$ [after Dick et al., 2003]. Three oblique segments (OS1, OS2, and OS3) form the $>200 \mathrm{~km}$ long oblique supersegment. The oblique supersegment is classified as ultraslow, being devoid of AVR, and having instead localized volcanic centers (Joseph Mayes Seamount, Narrowgate cross-axis high) and ridgeparallel mantle peridotite blocks in the rift valley while the orthogonal supersegment, east of $16^{\circ} \mathrm{E}$, is classified as slow. 


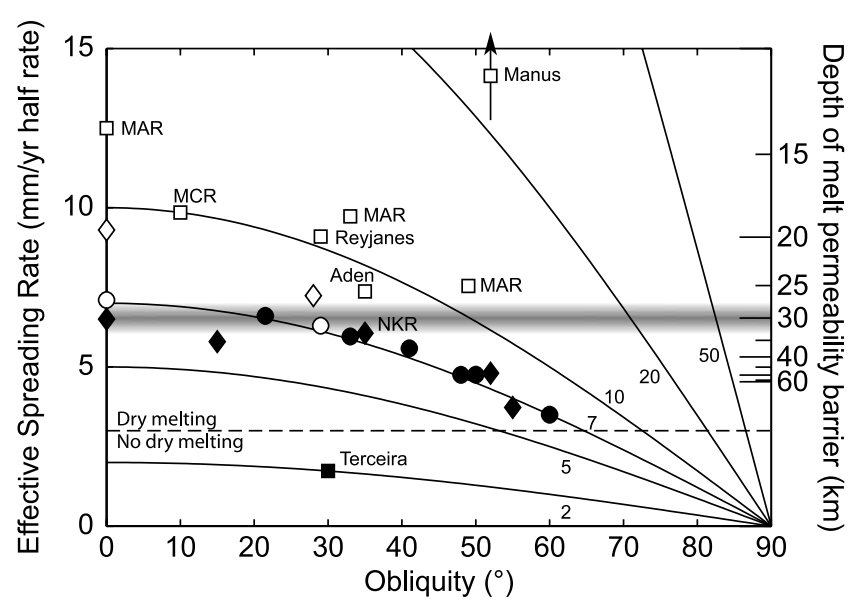

Figure 2. Effective spreading rate (left axis) and depth of the melt permeability barrier (right axis) for slow and ultraslow oblique ridges (open and filled symbols, respectively; see auxiliary material). Circles, SWIR; diamonds, Arctic ridges; squares, other ridges, individually labeled; solid lines, effective spreading rate for constant plate separation rate, labeled in $\mathrm{mm} / \mathrm{yr}$; shaded band, transition from slow to ultraslow spreading; dashed line, onset of dry melting.

recognized as the biharmonic equation for the $2 \mathrm{D}$ flow potential and Laplace's equation for the ridge-parallel velocity.

[13] The boundary conditions of equation 2 lead to classical solutions to each of the these two equations, easily expressed in cylindrical coordinates $\{r, \theta, y\}$ aligned with the ridge axis, with $r$ the radial distance from the ridge and $\theta$ the angle from the vertical. The $2 \mathrm{D}$ flow potential follows the corner flow solution [Batchelor, 1967].

$$
\phi=\frac{2}{\pi} V_{E} r \theta \cos \theta
$$

but with the effective spreading $V_{E}$ rate replacing the total plate velocity $V_{P}$. The ridge parallel velocity follows a shear flow solution

$$
v_{y}=\frac{2}{\pi} V_{S} \theta
$$

similar to that beneath a transform fault.
[14] In summary, the mantle flow underneath an oblique spreading center is simply the superposition of two decoupled flow fields, the first corresponding to mantle flow under an orthogonal ridge spreading with half-rate $V_{E}$, and the second to mantle flow beneath a transform slipping at $2 V_{S}$ (Figure 3).

\section{Thermal Structure}

[15] The amount of melt produced beneath a ridge segment depends on the upwelling rate and temperature structure. The latter reflects the balance between heat conduction and advection. Because the oblique ridge model considered here is invariant in $y$, there can be no ridge parallel temperature gradient. Therefore, only the corner flow component of equation 5 enters the heat equation. Consequently, the thermal problem is controlled by a single length scale

$$
L^{*}=\kappa / V_{E},
$$

where $\kappa$ is the thermal diffusivity. We use $\kappa=10^{-6} \mathrm{~m}^{2} / \mathrm{s}$ throughout this analysis.

[16] If $x$ and $z$ are scaled by $L^{*}$, the thermal structure of any oblique ridge collapses onto a universal thermal structure visualized in Figure 4a. A similar solution is given by Reid and Jackson [1981] and White et al. [2001], among others, who discuss the effect of melting on the thermal structure.

[17] Melting begins at $\sim 100 \mathrm{~km}$ depth and is initially limited by the water content of the rising mantle [Asimow and Langmuir, 2003] but volumetrically significant melting occurs when the dry solidus is met, near $60 \mathrm{~km}$ depth [e.g., Langmuir et al., 1992].

[18] If all the melt produced underneath ridge is extracted, the expected crustal thickness becomes

$$
H_{c}=\frac{1}{V_{E}} \iint v_{z} \frac{\partial F}{\partial z} d x d z
$$

where $F$ is the melt fraction, which depends on the relation between temperature and the solidus. Therefore, ridge obliquity influences crustal thickness in three ways: (1) a geometrical effect $1 / V_{E}$ representing the reduced plate area accreted per unit length of the ridge; (2) a kinematic effect $v_{z}$ representing the reduced upwelling velocity; (3) a thermal effect, as the melt productivity $\partial F / \partial z$ depends on $L^{*}$. Vogt et

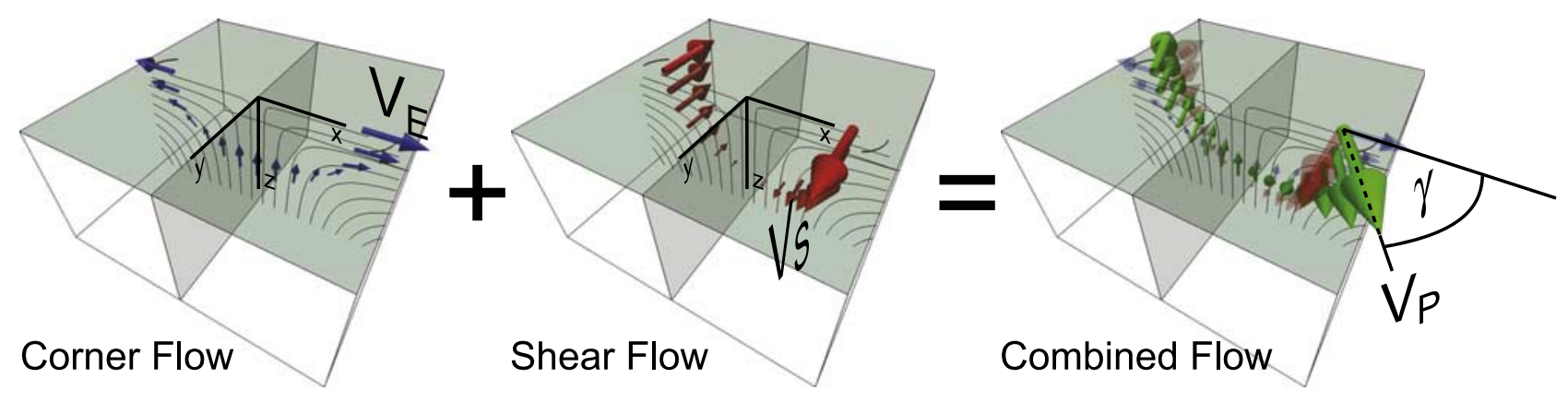

Figure 3. Decomposition of mantle flow underneath a ridge with $60^{\circ}$ obliquity into corner flow and shear flow components. 

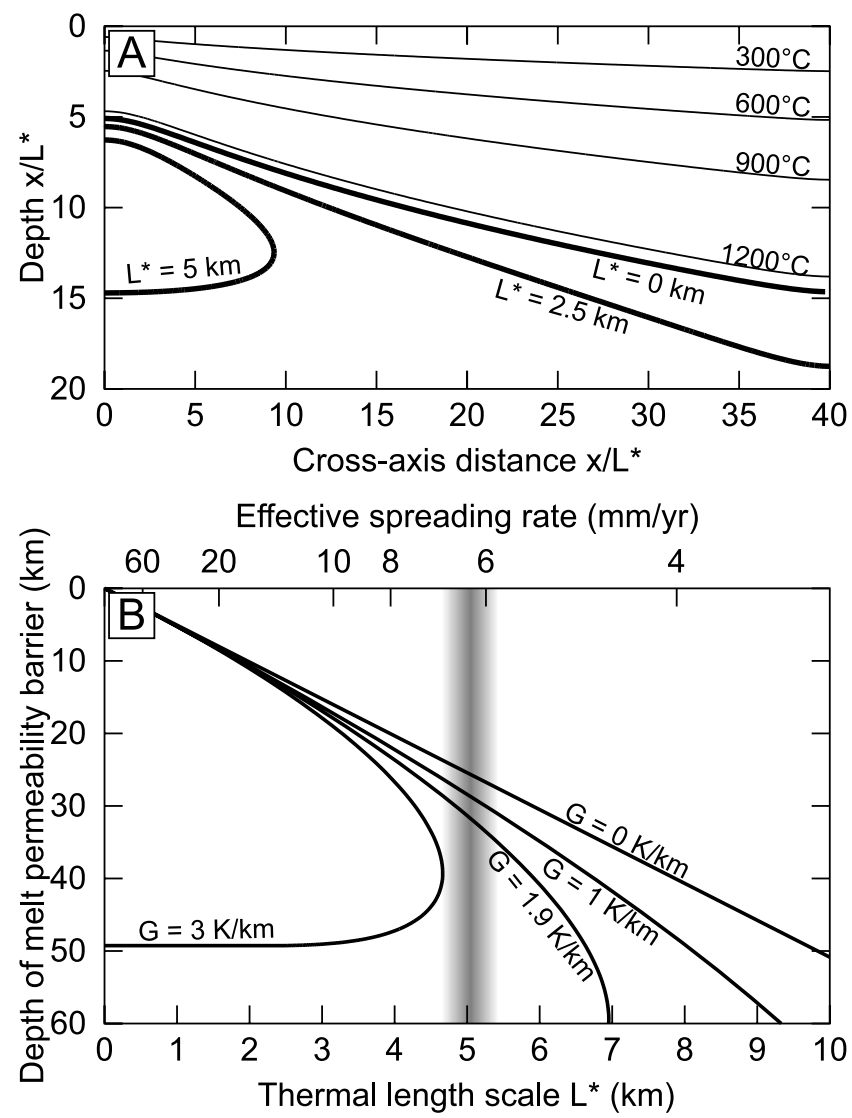

Figure 4. (a) Universal thermal structure underneath a mid-ocean ridge, calculated using the Finite Element software $\mathrm{COMSOL}^{\circledR}$, equation $5, T=0$ and $1370^{\circ} \mathrm{C}$ at $z / L^{*}=0$ and 200 , respectively, and convective flux at the side walls. The thin lines follow isotherms while the thick lines mark the permeability barrier for $L^{*}=0$ to $5 \mathrm{~km}$, defined as $T=1240^{\circ} \mathrm{C}+G z$ with $G=1.9^{\circ} / \mathrm{km}$ (assuming a density of $3300 \mathrm{~kg} . \mathrm{m}-3$ ). (b) Minimum depth of the melt permeability barrier as a function of $L^{*}$ and $G$.

al. [1969], Cannat et al. [1999], and Dick et al. [2003] have argued, using the kinematic effect, that crustal thickness depends primarily on the effective spreading rate. However, as upwelling velocities scale directly with $V_{E}$, this effect is exactly canceled by the geometric effect. Nevertheless, within the limits of this simple analytical flow model, the crustal thickness is indeed a unique function of effective spreading rate because of the thermal effect.

[19] Melts, being buoyant and forming vertical channels, travel quickly upward until they encounter a permeability barrier near $1240^{\circ} \mathrm{C}$ [Sparks and Parmentier, 1991]. The shallowest depth reached by this isotherm, $z_{1240}=5.1 L^{*}$ underneath the ridge axis (Figure 4), provides a simple relationship between the base of the lithosphere and the effective spreading rate.

[20] However, if the permeability barrier corresponds to plagioclase saturation [Kelemen and Aharonov, 1998], its temperature probably increases with depth. Therefore, the lithosphere is thicker than $z_{1240}$ (Figure 4b). Yang et al. [1996] determined that the temperature of the plagioclase multiple saturation point increases by $58^{\circ}$ per GPa. In that case the permeability barrier reaches $\sim 30 \mathrm{~km}$ depth at the slow/ultraslow transition $\left(L^{*}=5 \mathrm{~km}\right)$.

[21] Temperature-dependent viscosity and coupling between shear and corner flow for non-linear rheologies would thin the lithosphere underneath the ridge axis [Behn et al., 2007]. Variations in mantle temperature should also affect the relation between $V_{E}$ and thermal structure reported here [Cannat et al., 1999].

\section{Discussion and Conclusions}

[22] Ultraslow spreading, identified with the absence of continuous volcanism along axis, corresponds to $V_{E} \lesssim$ $6.5 \mathrm{~mm} / \mathrm{yr}$. Significant melting is excepted at every ultraslow ridge except for the Terceira Rift (Figure 2), which is probably influenced by the Azores hotspot [Vogt and Jung, 2004].

[23] Thus, the transition from slow to ultraslow spreading does not appear linked to a shutdown in melt production. Rather, we propose that the transition reflects inefficient vertical melt extraction at ultraslow ridges. This inefficiency may be caused by in-situ magma crystallization and/or prevention of hydrofractures. At ultraslow ridges, reduced melt volume and thick lithosphere may combine to prevent magma from reaching the surface. The high pressure at the depth of the permeability barrier may also prevent hydrofracturing. The localized volcanic centers seen at ultraslow ridges may result from a thermomechanical feedback process thinning the lithosphere and enabling volcanism over a limited area of the ridge axis [Cannat et al., 2003; Behn et al., 2007].

[24] The relation described here implies that the permeability barrier reaches $\sim 30 \mathrm{~km}$ depth at the slow/ultraslow spreading transition (Figure 2). Geochemical support for this inference includes MORB crystallization pressure of the order of 0.6 to $1 \mathrm{GPa}$ along the SWIR [Villiger et al., 2007] and Northern Knipovich Ridge [Hellevang and Pedersen, 2005] segments close to the slow/ultraslow transition. Lena trough peridotite geochemistry implies limited melting in the spinel stability field [Hellebrand and Snow, 2003], as expected at ultraslow ridges. Finally, the absence of $\mathrm{Eu}$ anomaly in cpx cores and the presence of opx instead of plagioclase in refertilized peridotite from the ultraslow SWIR oblique supersegment imply that melt addition occurred at depths greater than the plagioclase stability field ( 30 km) [Warren, 2007].

[25] Acknowledgments. This work was supported by NSF grants OCE-0327588, OCE-0548672, and OCE-0623188, OCE-0649103, the J. Lamar Worzel Assistant Scientist fund to LGJM and the Jessie B. Cox Endowed Fund to MDB. We thank Donna Blackman, Mathilde Cannat, Henry Dick, Don Forsyth, Daniel Sauter, Jeff Standish, and Jessica Warren for reviews, data and general insight on ultraslow spreading. $\mathrm{COMSOL}^{\circledR}$ is a registered trademark of COMSOL $\mathrm{AB}$.

\section{References}

Asimow, P. D., and C. H. Langmuir (2003), The importance of water to oceanic mantle melting regimes, Nature, 421, 815-820.

Atwater, T., and K. C. Macdonald (1977), Are spreading centers perpendicular to their transform faults?, Nature, 270, 715-719.

Batchelor, G. (1967), An Introduction to Fluid Dynamics, 615 pp. Cambridge Univ. Press, Cambridge, U. K

Behn, M. D., M. S. Boettcher, and G. Hirth (2007), Thermal structure of oceanic transform faults, Geology, 35(4), 307-310, doi:10.1130/ G23112A.1. 
Cannat, M., C. Rommevaux-Jestin, D. Sauter, C. Deplus, and V. Mendel (1999), Formation of the axial relief at the very slow spreading Southwest Indian Ridge $49^{\circ}$ to $69^{\circ} \mathrm{E}, J$. Geophys. Res., 104(B10), 22,825-22,843.

Cannat, M., C. Rommevaux-Jestin, and H. Fujimoto (2003), Melt supply variations to a magma-poor ultra-slow spreading ridge (Southwest Indian Ridge $61^{\circ}$ to $\left.69^{\circ} \mathrm{E}\right)$, Geochem. Geophys. Geosyst., 4(8), 9104, doi:10.1029/2002GC000480.

Cannat, M., D. Sauter, V. Mendel, E. Ruellan, K. Okino, J. Escartin, V. Combier, and M. Baala (2006), Modes of seafloor generation at a melt-poor ultraslowspreading ridge, Geology, 34(7), 605-608, doi:10.1130/G22486.1.

Dauteuil, O., and J.-P. Brun (1993), Oblique rifting in a slow-spreading ridge, Nature, 161, 145-148.

Dick, H. J. B., J. Lin, and H. Schouten (2003), An ultraslow-spreading class of ocean ridge, Nature, 426, 405-412.

Hellebrand, E., and J. E. Snow (2003), Deep melting and sodic metasomatism underneath the highly oblique-spreading Lena Trough (Arctic Ocean), Earth Planet. Sci. Lett., 216, 283-299.

Hellevang, B., and R. B. Pedersen (2005), Magmatic segmentation on the northern Knipovich Ridge: Evidence for high-pressure fractionation at an ultraslow spreading ridge, Geochem. Geophys. Geosyst., 6, Q09007, doi:10.1029/2004GC000898.

Kelemen, P. B., and E. Aharonov (1998), Periodic formation of magma fractures and generation of layered gabbros in the lower crust beneath oceanic spreading ridges, in Faulting and Magmatism at Mid-Ocean Ridges, Geophys. Monogr. Ser., vol. 106, edited by W. R. Buck et al., pp. 267-290, AGU, Washington, D. C.

Klingerhöfer, F., L. Géli, L. Matias, N. Steinsland, and J. Mohr (2000), Crustal structure of a super-slow spreading centre: A seismic refraction study of Mohns Ridge, $75^{\circ} \mathrm{N}$, Geophys. J. Int., 141, 509-526.

Langmuir, C. H., E. M. Klein, and T. Plank (1992), Petrological systematics of Mid-Ocean Ridge Basalts: Constraints on melt generation beneath ocean ridge, in Melt Flow and Melt Generation at Mid-Ocean Ridges, Geophys. Monogr. Ser., vol. 71, pp. 183-280, AGU, Washington, D. C.

Lin, J., and E. M. Parmentier (1990), A finite amplitude necking model of rifting in brittle lithosphere, J. Geophys. Res., 95(B4), 4909-4923.

Lin, J., and J. Phipps Morgan (1992), The spreading rate dependence of three-dimensional mid-ocean ridge gravity structure, Geophys. Res. Lett., 19, $13-16$.

McKenzie, D. P. (1969), Speculations on the consequences and causes of plate motions, Geophys. J. R. Astron. Soc., 18, 1-32.

Mendel, V., D. Sauter, C. Rommevaux-Jestin, P. Patriat, F. Lefebvre, and L. M. Parson (2003), Magmato-tectonic cyclicity at the ultra-slow spreading Southwest Indian Ridge: Evidence from variations of axial volcanic ridge morphology and abyssal hills pattern, Geochem. Geophys. Geosyst., 4(5), 9102, doi:10.1029/2002GC000417.

Michael, P. J., et al. (2003), Magmatic and amagmatic seafloor generation at the ultraslow-spreading Gakkel ridge, Arctic Ocean, Nature, 423, 956-961.
Phipps Morgan, J., and Y. J. Chen (1993), The genesis of oceanic crust: Magma injection, hydrothermal circulation, and crustal flow, J. Geophys. Res., 98, 6283-6297.

Reid, I., and H. R. Jackson (1981), Oceanic spreading rate and crustal thickness, Mar. Geophys. Res., 5, 165-172.

Sauter, D., H. Carton, V. Mendel, M. Munschy, C. Rommevaux-Jestin, J.-J. Schott, and H. Whitechurch (2004), Ridge segmentation and the magnetic structure of the Southwest Indian Ridge (at $50^{\circ} 30^{\prime} \mathrm{E}, 55^{\circ} 30^{\prime} \mathrm{E}$ and $66^{\circ} 20^{\prime} \mathrm{E}$ ): Implications for magmatic processes at ultraslow-spreading centers, Geochem. Geophys. Geosyst., 5, Q05K08, doi:10.1029/ 2003GC000581.

Searle, R., J. Keeton, R. Owens, R. White, R. Mecklenburgh, B. Parsons, and S. Lee (1998), The Reykjanes ridge: Structure and tectonic of a hot-spo influenced, slow-spreading ridge, from multibeam bathymetry, gravity and magnetic investigations, Earth Planet. Sci. Lett., 160, 463-478.

Sparks, D. W., and E. M. Parmentier (1991), Melt extraction from the mantle beneath spreading centers, Earth Planet. Sci. Lett., 105, 368-377.

Taylor, B., K. Crook, and J. Sinton (1994), Extensional transform zones and oblique spreading centers, J. Geophys. Res., 99(B10), 19,707-19,718.

Villiger, S., O. Müntener, and P. Ulmer (2007), Crystallization pressures of mid-ocean ridge basalts derived from major element variations of glasses from equilibrium and fractional crystallization experiments, J. Geophys. Res., 112, B01202, doi:10.1029/2006JB004342.

Vogt, P., and W. Jung (2004), The Terceira Rift as hyper-slow, hotspotdominated oblique spreading axis: A comparison with other slowspreading plate boundaries, Earth Planet. Sci. Lett., 218, 77-90.

Vogt, P., E. Schneider, and G. Johnson (1969), The crust and upper mantle beneath the sea, in The Earth's Crust and Upper Mantle, Geophys. Monogr. Ser, vol. 13, edited by J. Hart, pp. 556-617, AGU, Washington, D. C.

Warren, J. M. (2007), Geochemical and rheological constraints on the dynamics of the oceanic upper mantle, Ph.D. thesis, MIT/WHOI Joint Program in Oceanogr., Woods Hole, Mass.

White, R. S., T. A. Minshull, M. J. Bickle, and C. J. Robinson (2001), Melt generation at very slow-spreading oceanic ridges: Constraints from geochemical and geophysical data, J. Petrol, 42(6), 1171-1196.

Yang, H. J., R. J. Kinzler, and T. L. Grove (1996), Experiments and models of anhydrous, basaltic olivine-plagioclase-augite saturated melts from 0.001 to 10 kbar, Contrib. Mineral. Petrol., 124, 1-18.

M. D. Behn, Department of Marine Geology and Geophysics, Woods Hole Oceanographic Institution, WHOI MS \#24, Woods Hole, MA 02543, USA. (mbehn@whoi.edu)

L. G. J. Montési, Department of Geology, University of Maryland at College Park, College Park, MD 20742, USA. (montesi@umd.edu) 